\title{
Hydroxystreptomycin Production and Resistance in Streptomyces glaucescens
}

\author{
By HIDEO ONO, $\uparrow$ RETO CRAMERI, GILBERTO HINTERMANN AND \\ RALF HÜTTER* \\ Mikrobiologisches Institut, Eidgenössische Technische Hochschule, ETH-Zentrum, \\ CH-8092 Zürich, Switzerland
}

(Received 24 May 1982; revised 30 August 1982)

\begin{abstract}
The wild-type strain of Streptomyces glaucescens produces hydroxystreptomycin and shows an inherent natural resistance to streptomycin group aminoglycoside antibiotics. Cell free extracts of the wild-type strain were able to inactivate streptomycin, hydroxystreptomycin and dihydrostreptomycin in the presence of ATP. The phosphotransferase did not inactivate other aminoglycoside antibiotics, including spectinomycin.

Mutant strains were isolated, which were highly sensitive to streptomycin group aminoglycosides, had no measurable phosphotransferase activity and were unable to form detectable amounts of hydroxystreptomycin. This suggests either a correlation between phosphotransferase activity, streptomycin resistance and hydroxystreptomycin formation or defects in more than one gene in the strS mutant strains tested.
\end{abstract}

\section{INTRODUCTION}

Streptomyces glaucescens is capable of producing several antimicrobial compounds, of which hydroxystreptomycin (Hütter, 1967; Fig. 1) and the tetracenomycins (Weber et al., 1979, 1981) are chemically characterized. In addition a bacteriocin-like substance, glaucescin, is formed (Schurter et al., 1979; Crameri et al., 1981).

Streptomyces glaucescens is inherently more resistant to streptomycin than most other streptomycetes (Freeman \& Hopwood, 1978; Hütter et al., 1981). The natural streptomycin resistance is a genetically unstable character. The same phenomenon has also been observed with the streptomycin producers $S$. griseus and $S$. bikiniensis (Kirby \& Lewis, 1981). In $S$. glaucescens highly streptomycin-sensitive mutant strains arise spontaneously at a frequency of 0.2 to $1.4 \%$ (Hütter et al., 1981; Crameri et al., 1983). The frequency can be increased considerably by long-term cold storage of spores to $10 \%$ of the survivors or even higher (Suter $e t$ al., 1978), and by growing the organism on agar media containing ethidium bromide, the frequency of streptomycin-sensitive variants can be increased to nearly $100 \%$. Crossing experiments have shown that the genetically unstable streptomycin resistance is coded by a chromosomal gene (Hütter et al., 1981; Crameri et al., 1983).

In several streptomycetes various aminoglycoside modifying enzymes have been observed (Nimi et al., 1971 a, b; Miller \& Walker, 1969; Benveniste \& Davies, 1973; Walker \& Skorvaga, 1973; Dowding \& Davies, 1975; Davies et al., 1979; Piwowarski \& Shaw, 1979), primarily phosphotransferases and acetyltransferases (Davies et al., 1979). Streptomyces glaucescens strain GLA0 exhibits aminoglycoside 3-acetyltransferase activity (Davies et al., 1979) capable of inactivating gentamicin and tobramycin, but inactive against streptomycin group antibiotics.

In this work we describe the connection between phosphotransferase activity, hydroxystreptomycin production and natural streptomycin resistance in the wild-type strain of $S$. glaucescens.

† Present address: Takeda Chemical Ind., Central Research Division, Jusohonmachi 2, Yodogawa-ku, Osaka 532, Japan. 


\section{Table 1. Strains of Streptomyces glaucescens}

\begin{tabular}{|c|c|c|}
\hline Strain number & Genetic markers* & Mutagenic treatment + \\
\hline GLA0 & Wild-type & None \\
\hline GLA205 & strS, melC & Cold storage \\
\hline GLA208 & $a m f$ & Cold storage \\
\hline GLA209 & strs, melC & Cold storage \\
\hline GLA212 & strS, melC & EB \\
\hline GLA408 & melB & UV \\
\hline GLA1200 & strS & EB \\
\hline GLA1204 & strS, melC & EB \\
\hline GLA 1208 & strS, melC & EB \\
\hline GLA 1210 & melC & EB \\
\hline GLA1211 & melc & EB \\
\hline GLA1212 & str $S$, melc & EB \\
\hline GlA212 Str $^{r}$ & $\mathrm{Str}^{\mathrm{r}}$, melC & $\mathrm{AO}$ \\
\hline
\end{tabular}

* Marker designations are: amf, aerial mycelium formation negative; mel, melanin negative (Hütter et al., 1981), strS, streptomycin supersensitive (Hütter et al., 1981; Crameri et al., 1983).

+ EB, ethidium bromide; AO, acridine orange; UV, irradiation; cold storage, for details see Crameri et al. (1983). Strain GLA212 Str $^{\mathrm{r}}$ was selected as a revertant of strain GLA212 on agar plates containing $6 \mu \mathrm{mol} \mathrm{AO}^{-1}$ and is streptomycin resistant (growth on media containing $\geqslant 5 \mu \mathrm{g}$ streptomycin $\mathrm{ml}^{-1}$ ).

\section{METHODS}

Strains. Wild-type Streptomyces glaucescens strain GLA0 (= ETH 22794; Baumann et al., 1974, Hütter et al., 1981) and mutant strains employed are listed in Table 1. Staphylococcus aureus strain 209P (=ATCC 6538P) served as test organism for hydroxystreptomycin activity. In addition a mutant derivative strain 209P $\operatorname{Str}^{\mathrm{r}}$, resistant to $>400 \mu \mathrm{g} \mathrm{ml}^{-1}$ of streptomycin was used. Both strains are insensitive to tetracenomycins and to glaucescin. Inhibitory activity against strain 209 but not against $209 \operatorname{Str}^{\mathrm{r}}$ could therefore be used directly to determine production of hydroxystreptomycin, the only major aminoglycoside antibiotic produced by strain GLA0.

Cultural conditions. Stock cultures of Streptomyces strains were maintained as described by Crameri et al. (1983). Liquid cultures required for the determination of antibiotic production were prepared in a complex medium of the following composition: D-glucose, $0.5 \%(\mathrm{w} / \mathrm{v})$; soluble starch, $2 \%(\mathrm{w} / \mathrm{v})$; soy bean flour, $2 \%(\mathrm{w} / \mathrm{v})$; proteose, peptone (Difco) $0.5 \%$ (w/v); meat extract (Lab-Lemco powder, Oxoid) $0.5 \%(\mathrm{w} / \mathrm{v}) ; \mathrm{NaCl}, 0.3 \%\left(\mathrm{w} / \mathrm{v}\right.$ ) and $\mathrm{CaCO}_{3}$, $1 \%$ (w/v). The $\mathrm{pH}$ was adjusted to 7.0 with $1 \mathrm{~mol} \mathrm{NaOH} 1^{-1}$.

For testing aminoglycoside phosphotransferase activity, the Streptomyces strains were grown on three media described by Benveniste \& Davies (1973). Medium A corresponds to the medium used for $S$. kanamyceticus and $S$. spectabilis, medium B to that used for $S$. coelicolor and medium $\mathrm{C}$ to that used for $S$. fradiae.

Staphylococcus aureus was grown for $18 \mathrm{~h}$ at $37^{\circ} \mathrm{C}$ on slants of trypticase soy agar (Becton, Dickinson \& Co., Cockeysville, Md, U.S.A.). The cells were then washed from the slants with deionized water ( $5 \mathrm{ml})$, centrifuged $(10000 \mathrm{~g}, 5 \mathrm{~min})$, resuspended in $50 \%(\mathrm{v} / \mathrm{v})$ glycerol $(2 \mathrm{ml})$ and stored at $-70^{\circ} \mathrm{C}$.

Determination of hydroxystreptomycin and hydroxystreptomycin 6-phosphate production. Erlenmeyer flasks $\left(500 \mathrm{ml}\right.$ with four baffles) containing medium $(100 \mathrm{ml})$ were inoculated with about $10^{7}$ spores and incubated on a rotary shaker $\left(120\right.$ r.p.m.) at $30^{\circ} \mathrm{C}$ for 4 to 7 d. During the fermentation period samples of the cultures were centrifuged $(30000 \mathrm{~g}, 15 \mathrm{~min})$. Petri plates $(90 \mathrm{~mm})$ were prepared, filled with trypticase soy agar $(12 \mathrm{ml})$ and inoculated with about $5 \times 10^{3}$ indicator bacteria $\mathrm{ml}^{-1}$. The culture supernatant $(50 \mu \mathrm{l})$ was transferred into holes (diam. $8 \mathrm{~mm}$; prepared with a cork borer). After $18 \mathrm{~h}$ incubation at $37^{\circ} \mathrm{C}$ the inhibition zones were measured. The amount of antibiotic produced was quantified by comparison with standards. The relative potency of hydroxystreptomycin in comparison to streptomycin (base) was determined as $61 \%$.

Hydroxystreptomycin 6-phosphate was determined as antibiotically active hydroxystreptomycin after dephosphorylation with alkaline phosphatase III (final concentration 1.5 units $\mathrm{ml}^{-1}$ ) for $2 \mathrm{~h}$ at $37^{\circ} \mathrm{C}$

Determination of MIC. Spores and mycelia of the wild-type strain GLA0 and of its mutant derivatives were harvested from agar slants, ground with a glass rod in a test tube and suspended in $50 \mathrm{mmol}$ Tris/ $\mathrm{HCl}$ buffer $\mathrm{l}^{-1}$, $\mathrm{pH} 7 \cdot 3$, containing $0 \cdot 001 \%(\mathrm{v} / \mathrm{v})$ Triton X-100. Samples of the suspensions (about $10^{7} \mathrm{c} . \mathrm{f} . \mathrm{u}$.) were plated on yeast extract/malt extract agar containing a range of antibiotic concentrations, starting with $100 \mu \mathrm{g} \mathrm{ml}^{-1}$ and using $1: 2$ dilutions down to $0 \cdot 1 \mu \mathrm{g} \mathrm{ml}^{-1}$. The plates were then incubated for $4 \mathrm{~d}$ at $30^{\circ} \mathrm{C}$. MIC values $\left(\mu \mathrm{g} \mathrm{ml}^{-1}\right)$ for a given antibiotic are those able to inhibit completely the growth of the strain tested.

Preparation of cell free extracts. The mycelium from cultures $(100 \mathrm{ml})$ in medium A was collected by centrifugation $(30000 \mathrm{~g}, 15 \mathrm{~min})$, washed with sterile deionized water and resuspended in $40 \mathrm{ml}$ of $0.01 \mathrm{ml}$ Tris/ $\mathrm{HCl}$ buffer $1^{-1}, \mathrm{pH} 7 \cdot 8$, containing $10 \mathrm{mmol} \mathrm{MgCl}_{2} 1^{-1}, 10 \mathrm{mmol} \mathrm{NH}_{4} \mathrm{Cl}^{-1}$ and $5 \mathrm{mmol}$ mercaptoethanol $\mathrm{1}^{-1}$. 
Cells were disrupted by ultrasonication according to Crameri et al. (1982). The resulting suspension was centrifuged for $30 \mathrm{~min}$ at $30000 \mathrm{~g}$. DNAase I (bovine pancreas) was added to the supernatant (final concentration of $\left.4 \mu \mathrm{g} \mathrm{ml}^{-1}\right)$. After a further centrifugation $(105000 \mathrm{~g}, 4 \mathrm{~h})$ to pellet the ribosomes, the supernatant was dialysed overnight against at least 10 volumes of the same buffer. Dialysed samples were stored at $-20^{\circ} \mathrm{C}$.

Assay for hydroxystreptomycin phosphorylating enzymes. To $250 \mu \mathrm{l}$ of cell free extract from cells pregrown in medium A, $250 \mu \mathrm{l}$ of the following solution were added: $156 \mu$ mol hydroxystreptomycin $1^{-1}, 0 \cdot 29$ mmol ATP $1^{-1}$, $1.95 \mathrm{mmol}$ Tris $/ \mathrm{HCl}^{-1}, \mathrm{pH} 7.8,0.78 \mathrm{mmol} \mathrm{MgCl} \mathrm{l}^{-1}$ and $0.1 \mathrm{mmol}$ dithioerythritol $\mathrm{l}^{-1}$. After incubation for $2 \mathrm{~h}$ at $30^{\circ} \mathrm{C}$ with gentle agitation, the reaction mixture was treated for $5 \mathrm{~min}$ at $10{ }^{\circ} \mathrm{C}$ to stop the reaction. Residual antibiotic activity was determined as described above for hydroxystreptomycin production. The amount of inactivation was calculated from the remaining biological activity in the reaction mixture, in comparison to a control without cell free extract.

For the reactivation of inactivated hydroxystreptomycin samples $(100 \mu \mathrm{l})$ were treated with Escherichia coli alkaline phosphatase III (final concentration 1.5 units $\mathrm{ml}^{-1}$ ) for $2 \mathrm{~h}$ at $37^{\circ} \mathrm{C}$. The reaction was stopped by heating to $100^{\circ} \mathrm{C}$ for $5 \mathrm{~min}$, and the extent of restoration of antimicrobial activity was determined using Staphylococcus aureus strain $209 \mathrm{P}$ as test organism as described above.

Chemicals. The antibiotics and precursors used were as follows: ampicillin, novobiocin (sodium salt), oxytetracycline (hydrochloride), neomycin (sulphate), kanamycin (sulphate) and chloramphenicol (Sigma), streptomycin (sulphate) (Novo Industri, Copenhagen, Denmark), dihydrostreptomycin and erythromycin (base) (Serva, Heidelberg, F.R.G.), cephaloridin (Glaxo), hydroxystreptomycin (Abbott, Chicago, Ill, U.S.A.), spectinomycin (Upjohn, Kalamazoo, Mich., U.S.A.), gentamicin and antibiotic G-418 (Schering, Bloomfield, N.J., U.S.A.), rifampicin (Ciba-Geigy), paromomycin (Parke-Davis, Detroit, Mich., U.S.A.), spiramycin and deoxystreptamine (Kyowa Hakko, Tokyo, Japan), streptidine (H. Grisebach, Freiburg i.Br., F.R.G.).

Alkaline phosphatase type III (EC 3.1.3.1) was from Sigma, bovine pancreas DNAase (EC 3.1.4.5) from Calbiochem. Other chemicals were of highest available grades from Sigma, Merck or Fluka, Buchs SG, Switzerland.

\section{RESULTS}

\section{Production of hydroxystreptomycin by Streptomyces glaucescens}

The wild-type strain GLA0 of $S$. glaucescens was found to produce up to $88 \mu \mathrm{g}$ hydroxystreptomycin $\mathrm{ml}^{-1}$ in the complex fermentation medium (Fig. 2). The optimal temperature for antibiotic production was $30^{\circ} \mathrm{C}$, significantly below the optimal growth temperature which was $37^{\circ} \mathrm{C}$. In media containing inorganic phosphate antibiotically inactive hydroxystreptomycin 6-phosphate (see Fig. 1) was accumulated instead of the active antibiotic (Table 2).

\section{Natural resistance to streptomycin-type aminoglycoside antibiotics}

The susceptibility of the wild-type strain GLA0 and some of its derivatives to various antibiotics was tested. The results (Table 3 ) show that the increased antibiotic sensitivity of strains GLA1200, GLA1204, GLA1208 and GLA1212 is specific to the streptomycin group antibiotics dihydrostreptomycin, hydroxystreptomycin and streptomycin itself. The difference in absolute resistance levels in comparison to previously published values (Freeman \& Hopwood, 1978; Hütter et al., 1981) has to be attributed to test differences. Previously we used spores and tested the effect on spore germination and growth. In this study we used suspensions composed primarily of mycelial fragments to compensate for bad sporulation of some mutant strains. Mycelial fragments have already proven to be much more resistant than spores in other hydroxystreptomycin producers (Benedict et al., 1951) and furthermore the resistance level is highly dependent on the physiological age of the culture (Cella \& Vining, 1975; Piwowarski \& Shaw, 1979).

\section{Hydroxystreptomycin phosphotransferase activity}

Cell free extracts of the wild-type strain GLA0 were tested for the ability to inactivate hydroxystreptomycin by phosphorylation. Hydroxystreptomycin was inactivated by cell free extracts only in the presence of ATP (Fig. 3a). Inactivation was dependent on extract quantity and incubation time following classical saturation kinetics; 1 mol phosphate was required for the inactivation of $1 \mathrm{~mol}$ strentomycin (data not shown). Cell free extracts from mycelia grown 


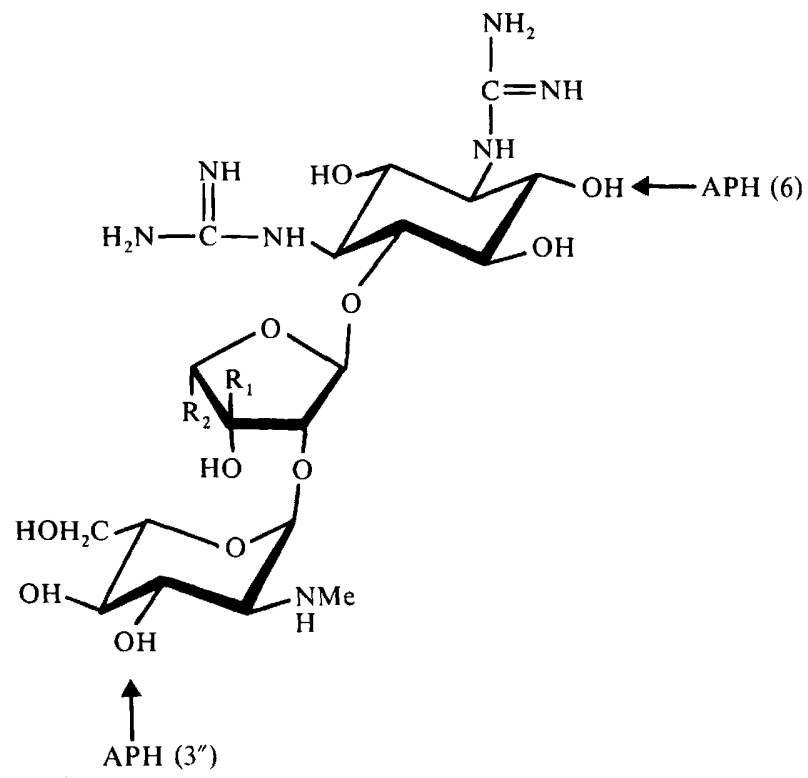

Fig. 1. Chemical structure of hydroxystreptomycin, streptomycin and dihydrostreptomycin. For hydroxystreptomycin $\mathrm{R}_{1}=\mathrm{CHO}$ and $\mathrm{R}_{2}=\mathrm{CH}_{2} \mathrm{OH}$; for streptomycin $\mathrm{R}_{1}=\mathrm{CHO}$ and $\mathrm{R}_{2}=\mathrm{CH}_{3}$; for dihydrostreptomycin $\mathrm{R}_{1}=\mathrm{CH}_{2} \mathrm{OH}$ and $\mathrm{R}_{2}=\mathrm{CH}_{3} ; \mathrm{APH}$ denotes aminoglycoside phosphotransferase.

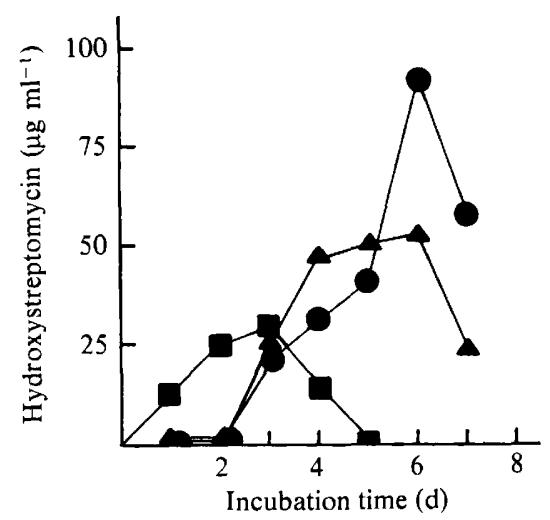

Fig. 2. Hydroxystreptomycin production in Streptomyces glaucescens strain GLA0 at different incubation temperatures. $\triangle, 26^{\circ} \mathrm{C} ; 0,30^{\circ} \mathrm{C} ; \mathbf{\square}, 37^{\circ} \mathrm{C}$.

Table 2. Influence of media composition on the production of hydroxystreptomycin and hydroxystreptomycin phosphate by $S$. glaucescens strain GLAO

The cultures were grown for $7 \mathrm{~d}$ on the media A, B and C described by Benveniste \& Davies (1973). Media A and B contain inorganic phosphate, medium $C$ does not. Cultures were harvested and antibiotic activity was tested in the supernatant. Phosphotransferase activity was tested in cell free extracts. For details see Methods. Antibiotic concentrations were determined after growth for $7 \mathrm{~d}$ at $30^{\circ} \mathrm{C}$. Hydroxystreptomycin was determined in untreated culture supernatants. Hydroxystreptomycin 6-phosphate was analysed as described in Methods (see Fig. $3 b$ ).

$\begin{array}{cccr}\text { Growth medium } & \begin{array}{c}\text { Hydroxystreptomycin } \\ \left(\mu \mathrm{g} \mathrm{ml}^{-1}\right)\end{array} & \begin{array}{c}\text { Hydroxystreptomycin } \\ \text { phosphate }\left(\mu \mathrm{g} \mathrm{ml}^{-1}\right)\end{array} & \begin{array}{r}\text { Phosphotran } \\ \text { activity }\end{array} \\ \text { A } & <1 & 48 & 100 \\ \text { B } & <1 & 45 & 32 \\ \text { C } & 74 & <1 & <5\end{array}$

* Arbitrary units. Highest activity in extracts from medium A was taken as $100 \%$, corresponding to total inactivation of the antibiotic under standard test conditions (see Methods). 
Table 3. Susceptibility of Streptomyces glaucescens strain GLAO and mutant derivatives to various antibiotics

\begin{tabular}{lcccccc} 
& \multicolumn{5}{c}{ MIC values $\left(\mu \mathrm{g} \mathrm{ml}^{-1}\right)$} \\
\cline { 2 - 6 } & GLA & GLA & GLA & GLA & GLA & GLA \\
Hydroxystreptomycin & 0 & 1210 & 1200 & 1204 & 1208 & 1212 \\
Streptomycin & 100 & $>100$ & $3 \cdot 13$ & $3 \cdot 13$ & $3 \cdot 13$ & $3 \cdot 13$ \\
Dihydrostreptomycin & $>100$ & $>100$ & $1 \cdot 56$ & $1 \cdot 56$ & $1 \cdot 56$ & $1 \cdot 56$ \\
Kanamycin & 100 & $>100$ & $1 \cdot 56$ & $1 \cdot 56$ & $1 \cdot 56$ & $1 \cdot 56$ \\
Neomycin & $1 \cdot 56$ & $1 \cdot 56$ & $0 \cdot 78$ & $0 \cdot 39$ & $0 \cdot 78$ & $0 \cdot 78$ \\
Paromomycin & $12 \cdot 5$ & $6 \cdot 25$ & $3 \cdot 13$ & $1 \cdot 56$ & $3 \cdot 13$ & $3 \cdot 13$ \\
Spectinomycin & $6 \cdot 25$ & $6 \cdot 25$ & $6 \cdot 25$ & $1 \cdot 56$ & $3 \cdot 13$ & $3 \cdot 13$ \\
Gentamicin & 25 & 25 & 25 & 25 & $12 \cdot 5$ & $12 \cdot 5$ \\
G-418 & $6 \cdot 25$ & $6 \cdot 25$ & $3 \cdot 13$ & $6 \cdot 25$ & $3 \cdot 13$ & $6 \cdot 25$ \\
Ampicillin & 50 & 25 & 25 & $6 \cdot 25$ & $12 \cdot 5$ & $12 \cdot 5$ \\
Cephaloridin & 50 & 50 & 50 & 100 & $>100$ & 100 \\
Oxytetracycline & 25 & 25 & 25 & 25 & 25 & 25 \\
Chloramphenicol & $3 \cdot 13$ & $3 \cdot 13$ & $12 \cdot 5$ & $3 \cdot 13$ & $1 \cdot 56$ & $1 \cdot 56$ \\
Erythromycin & $12 \cdot 5$ & $12 \cdot 5$ & 25 & 25 & $12 \cdot 5$ & $12 \cdot 5$ \\
Spiramycin & 25 & 25 & $>100$ & 50 & 25 & 25 \\
Novobiocin & 50 & 50 & $>100$ & 50 & 50 & 50 \\
Rifampicin & $0 \cdot 78$ & $0 \cdot 78$ & $0 \cdot 78$ & $0 \cdot 2$ & $0 \cdot 2$ & $0 \cdot 2$
\end{tabular}
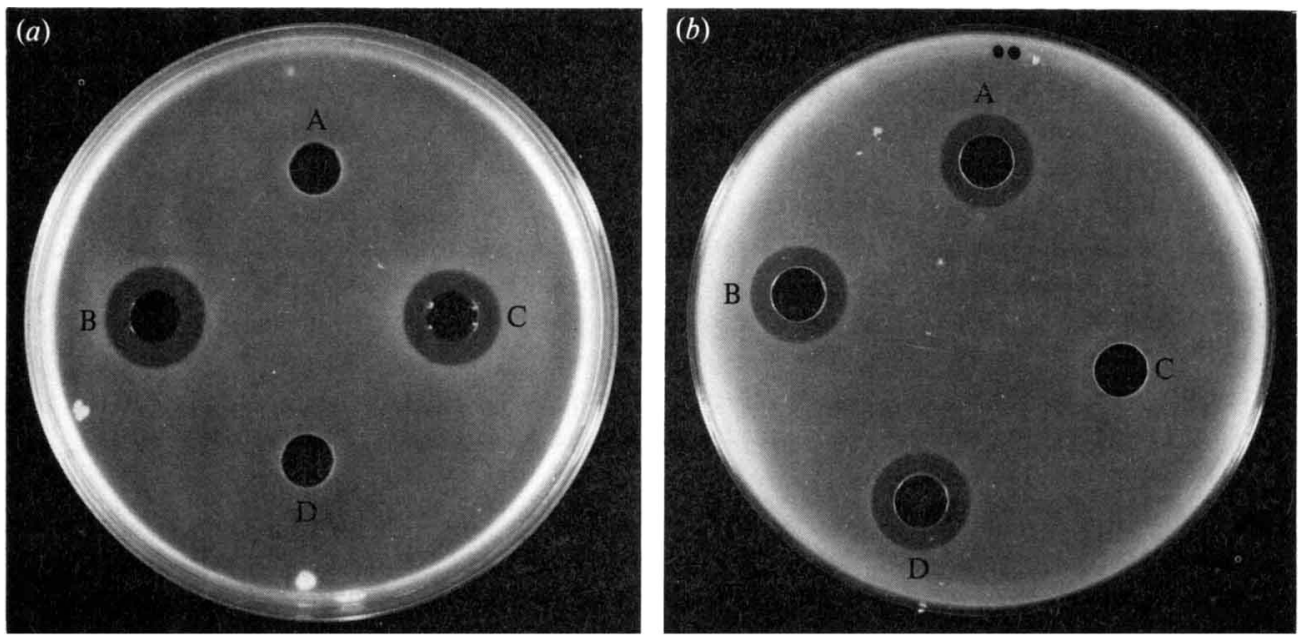

Fig. 3. (a) Inactivation of hydroxystreptomycin by cell free extracts of Streptomyces glaucescens strain GLA0. Hydroxystreptomycin $\left(25 \mu \mathrm{g} \mathrm{ml}^{-1}\right)$. A, Complete incubation mixture (see Methods), inactivation $>99 \% ; B$, no cell free extract; C, no ATP; D, no hydroxystreptomycin. (b) Inactivation of hydroxystreptomycin by cell free extracts from Streptomyces glaucescens strain GLA0 and reactivation by treatment with alkaline phosphatase III. A, Hydroxystreptomycin $\left(25 \mu \mathrm{g} \mathrm{m}^{-1}\right)$; B, with addition of alkaline phosphatase III (control); C, with addition of cell free extract with phosphotransferase activity; D, sample $\mathrm{C}$ treated with alkaline phosphatase III. For details see Methods.

on medium A had the highest specific activity $(100 \%)$, extracts from medium B grown cells exhibited about $30 \%$ activity, while extracts from medium $\mathrm{C}$ grown cells had no detectable phosphorylating activity (Table 2).

The biological activity of the inactivated hydroxystreptomycin could be restored by treating the samples with alkaline phosphatase III (Fig. 3b). Furthermore direct incorporation of ${ }^{32} \mathrm{P}$ was also detected with streptomycin and [ $\gamma^{-32}$ P]ATP (J. Davies, personal communication), thus hydroxystreptomycin inactivation was caused by the activity of a phosphotransferase. 


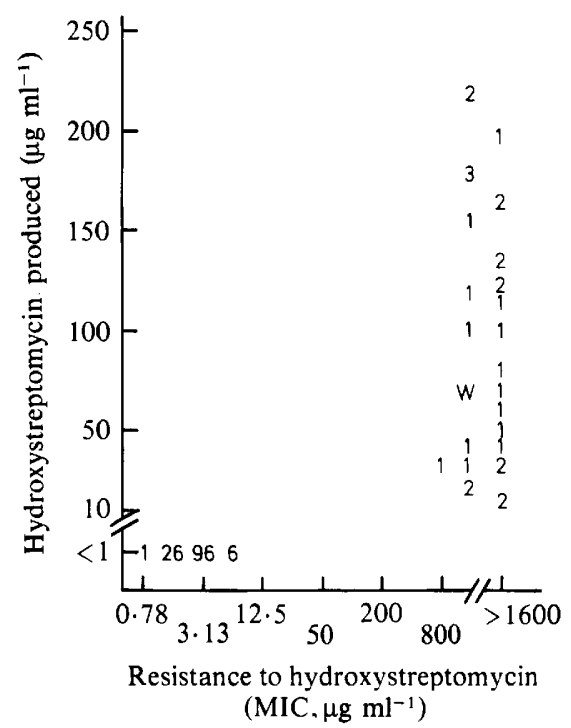

Fig. 4. Relationship between hydroxystreptomycin production and resistance in Streptomyces glaucescens GLA0 and 160 of its derivatives isolated after ethidium bromide treatment. The numbers designate the number of strains tested exhibiting the phenotypes defined by the coordinates. W indicates the wild-type strain GLA0.

The substrate profile of the phosphotransferase was determined using a number of aminoglycoside antibiotics. Only dihydrostreptomycin, hydroxystreptomycin and streptomycin were strongly phosphorylated. Thus, after incubation with phosphotransferase from strain GLA0 (standard conditions) hydroxystreptomycin exhibited $5 \%$ residual activity, streptomycin $17 \%$ and dihydrostreptomycin $31 \%$. Neomycin, kanamycin, gentamicin, antibiotic G-418, paromomycin and spectinomycin were not inactivated. Studies with $\left[\gamma^{-32} \mathrm{P}\right] \mathrm{ATP}$ revealed no incorporation of the radioactive label into neomycin, kanamycin and sisomicin (J. Davies, personal communication), confirming the substrate specificity of the phosphotransferase. The enzyme preparation was, however, capable of phosphorylating streptidine efficiently (data not shown), suggesting the presence of a 6-phosphotransferase.

\section{Simultaneous loss of hydroxystreptomycin production, streptomycin resistance and phosphotransferase activity}

As shown by Suter et al. (1978) ethidium bromide induces specific types of mutations in strain GLA0 of $S$. glaucescens. In a separate study 160 surviving clones were isolated from strain GLA0 after incubation for $6 \mathrm{~d}$ at $37^{\circ} \mathrm{C}$ on agar medium containing $7 \mu \mathrm{mol}$ ethidium bromide $1^{-1}$. One hundred and twenty-nine clones $(81 \%$ of total) were hydroxystreptomycin sensitive and among these $128(80 \%$ of total) were also melanin negative. Nine strains $(5.6 \%)$ were aerial mycelium negative, and the remaining clones did not show any changes in their phenotypes. No auxotrophic or temperature-sensitive mutant strains were found among the survivors.

The hydroxystreptomycin production of these 160 strains was tested and plotted against the level of resistance towards the same antibiotic (Fig. 4). None of the hydroxystreptomycinsensitive strains produced any detectable amount of hydroxystreptomycin; production was detected, however, in all strains with resistance levels comparable to those of the wild-type strain GLA0. Similarly, two other streptomycin-sensitive mutant strains GLA205 and GLA209, which were derived from the wild-type strain after cold storage, showed no detectable hydroxystreptomycin production. Changes in culture conditions (medium, growth temperature, incubation time) or repeated transfer to fresh medium did not lead to antibiotic production. No cosynthesis was found with combinations of mutant strains on either agar plates or in liquid media. Furthermore supplementation of the media with the biosynthetic precursors streptidine 
or deoxystreptamin did not restore antibiotic production. Additional studies have shown, that streptomycin-sensitive mutant strains are unable to produce hydroxystreptomycin-phosphate on various media, while the wild-type strain accumulated hydroxystreptomycin-phosphate in liquid media containing inorganic phosphate (Table 2).

Hydroxystreptomycin phosphotransferase activity was only measurable in hydroxystreptomycin-resistant strains such as the wild-type strain GLA0 or the mutant strains GLA208, GLA408, GLA1210 or GLA1211. However, none of the sensitive mutant strains showed any detectable phosphotransferase activity. The hydroxystreptomycin resistant revertant strain GLA212 Str ${ }^{\mathrm{r}}$, derived from the sensitive mutant strain GLA212, did not exhibit any phosphotransferase activity, and no hydroxystreptomycin was detectable in the fermentation broth.

\section{DISCUSSION}

Antibiotic producing micro-organisms are usually more resistant towards their own antibiotics than non-producing strains (Demain, 1974; Vining, 1979). This has also been observed in the hydroxystreptomycin producing $S$. glaucescens strain GLA0 (Freeman \& Hopwood, 1978; Hütter et al., 1981). It was initially thought, that the inherent resistance was due, in the absence of modifying enzymes, to low accumulation of streptomycin-type aminoglycosides from the environment, but it was later found that the strains synthesized a specific phosphotransferase (J. Davies, personal communications; Hütter et al., 1981) capable of attacking dihydrostreptomycin, hydroxystreptomycin and streptomycin, but inactive with other aminoglycosides. The ability to produce phosphotransferase activity is frequently lost in $S$. glaucescens. This loss reduced specifically the inherent resistance of the wild-type strain towards streptomycin-type aminoglycosides but did not change the susceptibility pattern towards other antibiotics. Genetic investigations showed, that the loss of phosphotransferase activity is due to chromosomal mutations of unknown nature in the $s t r S^{+}$gene, or in closely linked genes in the str $S^{+}$region (Hütter et al., 1981; Crameri et al., 1983). We therefore concluded that the activity of the (hydroxy)streptomycin phosphotransferase is the main cause for the inherent resistance of the wild-type strain GLA0 of $S$. glaucescens towards streptomycin-type aminoglycosides.

Such a correlation between the synthesis of a phosphotransferase and streptomycin susceptibility is not new for streptomycin producing streptomycetes. It has already been demonstrated for $S$. bikiniensis by Piwowarski \& Shaw (1979) and was studied in S. griseus by Nimi et al. (1971 $a, b)$ and Sugiyama et al. $(1981 a, b)$ and to some extent by Hotta et al. (1981). We have at present no information, whether a decreased affinity of ribosomes or a reduced cell permeability (Cella \& Vining, 1975; Sugiyama et al., 1981 a, b; Yamamoto et al., 1981) are additional factors contributing at least to some extent to streptomycin resistance in $S$. glaucescens. But the fact that the loss of phosphotransferase activity in the $s t r S$ mutant strains reduces the level of resistance towards streptomycin-type aminoglycosides to that in other streptomycetes is evidence against a strong contribution of these two other factors. We rather assume, as postulated by Nimi et al. (1981), that externally added streptomycins are only transiently accumulated in the cell and then excreted again after phosphorylation. Accumulation data with $S$. glaucescens wild-type strain GLA0 (Hütter et al., 1981) are in agreement with such an assumption.

As the phosphotransferase activity was lost completely in the mutant strain and since $1 \mathrm{~mol}$ ATP was sufficient to inactivate $1 \mathrm{~mol}$ hydroxystreptomycin, we assume that only one type of phosphotransferase was synthesized by our strain and that we are not dealing with diphosphorylations (Walker \& Skorvaga, 1973). The phosphorylation of streptidine by our enzyme preparation strongly supports the assumption, that our strain contains a (hydroxy)streptomycin 6-phosphotransferase (Walker, 1975b).

The high specificity of the phosphotransferase activity for streptomycin-type aminoglycosides, including hydroxystreptomycin, seems to support the hypothesis that phosphotransferase is involved in hydroxystreptomycin biosynthesis. The effect of phosphate on hydroxystreptomycin production also supports this assumption. In media containing inorganic phosphate 
hydroxystreptomycin phosphate is accumulated, presumably due to phosphate repression of phosphatases (Miller \& Walker, 1970; Demain \& Inamine, 1970). In cells grown in media without inorganic phosphate hydroxystreptomycin production is high. A direct correlation between the production of unphosphorylated antibiotic and phosphatase levels has also been suggested by Shirafuji et al. (1977) based on studies with partially phosphatase defective mutant strains in the butirosin producing Bacillus vitellinus. The absence of detectable phosphotransferase activity in medium without inorganic phosphate might be attributed to a test artefact caused by high phosphatase levels, including ATPases. The same effect might also be responsible for the absence of detectable phosphotransferase activity in the phage resistant streptomycin producing $S$. griseus mutant mentioned in Ogawa \& Perlman (1976).

Walker $(1975 b)$ pointed out that possibly a number of intermediates in the biosynthetic pathway between streptidine 6-phosphate and streptomycin 6-phosphate, might become dephosphorylated by a streptomycin 6-phosphate phosphatase (Walker, 1975a) or other phosphatases. The streptomycin 6-phosphotransferase would then be necessary to salvage these products by rephosphorylation. Absence of the enzyme would lead to accumulation of dephosphorylated intermediates. On the other hand we can not exclude the possibility, that the strS mutation affects several genes either due to polarity or to large deletions.

The cloning of the $s t r S^{+}$gene and its reintroduction into $s t r S$ mutant strains of $S$. glaucescens will show whether such a direct correlation between phosphotransferase activity, streptomycin resistance and hydroxystreptomycin production exists or whether the strS mutant strains carry defects in more than one gene.

We thank H. Grisebach for the sample of streptidine, Kyowa Hakko Co. for the sample of deoxystreptamine, and J. Davies and T. Kieser for critical advice. The work was supported by a research grant from the Swiss Federal Institute of Technology, Zürich.

\section{REFERENCES}

Baumann, R., Hütter, R. \& Hopwood, D. A. (1974). Genetic analysis in a melanin-producing streptomycete : Streptomyces glaucescens. Journal of General Microbiology 81, 463-474.

BeNedict, R. G., Lindenfelser, L. A., Stodola, F. H. \& TRAufler, D. H. (1951). Studies on Streptomyces griseocarneus and the production of hydroxystreptomycin. Journal of Bacteriology 62, 487-497.

BeNVENISTE, R. \& Davies, J. (1973). Aminoglycoside antibiotic-inactivating enzymes in actinomycetes similar to those present in clinical isolates of antibiotic-resistant bacteria. Proceedings of the National Academy of Sciences of the United States of America 70, 2276-2280.

Cella, R. \& Vining, L. C. (1975). Resistance to streptomycin in a producing strain of Streptomyces griseus. Canadian Journal of Microbiology 21, 463472.

Crameri, R., Zatchej, M., Hintermann, G., SCHURTER, W. \& HüTTER, R. (1981). Chromosomal inheritance of glaucescin, a bacteriocin-like substance from Streptomyces glaucescens. FEMS Microbiology Letters 11, 243-247.

Crameri, R., EtTlinger, L., Hütter, R., LeRCh, K., Suter, M. \& VetTERLI, J. A. (1982). Secretion of tyrosinase in Streptomyces glaucescens. Journal of General Microbiology 128, 371-379.

Crameri, R., Kieser, T., ONo, H., Sanchez, J. \& HÜTTER, R. (1983). Chromosomal instability in Streptomyces glaucescens: mapping of streptomycinsensitive mutants. Journal of General Microbiology 129, 519-527.
Davies, J., Houk, C., Yagisawa, M. \& White, T. J. (1979). Occurrence and function of aminoglycosidemodifying enzymes. In Proceedings of the 3rd International Symposium on Genetics of Industrial Microorganisms, pp. 166-169. Edited by O. K. Sebek \& A. J. Laskin. Washington, D.C. : American Society for Microbiology.

DemaIN, A. L. (1974). How do antibiotic-producing microorganisms avoid suicide? Annals of the New York Academy of Sciences 235, 601-612.

DEMAIN, A. L. \& INAMINE, E. (1970). Biochemistry and regulation of streptomycin and regulation of mannosidostreptomycinase ( $\alpha$-D-mannosidase) formation. Bacteriological Reviews 34, 1-19.

Dowding, J. \& Davies, J. (1975). Mechanisms and origins of plasmid-determined antibiotic resistance. In Microbiology 1974, pp. 179-186. Edited by D. Schlessinger. Washington, D.C.: American Society for Microbiology.

Freeman, R. F. \& Hopwood, D. A. (1978). Unstable naturally occurring resistance to antibiotics in Streptomyces. Journal of General Microbiology 106, 377-381.

Hotta, K., Yamamoto, H., OKami, Y. \& Umezawa, H. (1981). Resistance mechanisms of kanamycin-, neomycin- and streptomycin-producing streptomycetes to aminoglycoside antibiotics. Journal of Antibiotics 34, 1175-1182.

HÜTTER, R. (1967). Systematik der Streptomyceten. Basel: Karger Verlag.

HÜTter, R., Kieser, T., Crameri, R. \& HintermanN, G. (1981). Chromosomal instability in Streptomyces 
glaucescens. Zentralblatt für Bakteriologie, Mikrobiologie und Hygiene (supplement) 11, 551-559.

KIRBY, R. \& LEWIS, E. (1981). Unstable genetic elements affecting streptomycin resistance in the streptomycin-producing organisms Streptomyces griseus NCIB 8506 and Streptomyces bikiniensis ISP 5235. Journal of General Microbiology 122, 351355.

Miller, A. L. \& Walker, J. B. (1969). Enzymatic phosphorylation of streptomycin by extracts of streptomycin-producing strains of Streptomyces. Journal of Bacteriology 99, 401-405.

MilleR, A. L. \& WALKER, J. B. (1970). Accumulation of streptomycinphosphate in cultures of streptomycin producers grown on a high-phosphate medium. Journal of Bacteriology 104, 8-12.

NimI, O., ITo, G., SuedA, S. \& NomI, R. (1971a). Phosphorylation of streptomycin at $\mathrm{C}_{6}-\mathrm{OH}$ of streptidine moiety by an intracellular enzyme of Streptomyces griseus. Agricultural and Biological Chemistry 35, 848-855.

Nimi, O., Ito, G., Ohata, Y., Funayama, S. \& Nomi, R. (1971b). Streptomycin-phosphorylating enzymes produced by Streptomyces griseus. Agricultural and Biological Chemistry 35, 856-861.

Nimi, O., Sugiyama, M., Kameoka, H., Tomoeda, H., ONO, K. \& NoMI, R. (1981). Fate of streptomycin in mycelium of the producer organism. Biotechnology Letters 3, 239-244.

OGaWa, Y. \& Perlman, D. (1976). The occurrence of streptomycin-phosphorylating enzymes in streptomycin producing streptomycetes. Journal of Antibiotics 29, 1112-1113.

Piwowarski, J. \& Shaw, P. D. (1979). Streptomycin resistance in a streptomycin-producing microorganism. Antimicrobial Agents and Chemotherapy 16, 176182.

SCHURTER, W., Kissling-ABderhalden, M. \& LeISINGER, T. (1979). Glaucescin, a bacteriocin-like substance from Streptomyces glaucescens. Journal of General Microbiology 113, 243-253.

Shirafuj, H., Nakahama, K., Nogami, A., KiDa, M. \& YONEDA, M. (1977). Accumulation of $6^{\prime}-N$ pyrophosphoamide butirosin A by phosphatase deficient mutant. Abstract of the Annual Meeting of the Agricultural Chemical Society of Japan, Yokohama, 156.

SugiYama, M., Mochizuki, H., Nimi, O. \& Nomi, R. $(1981 a)$. Roles of streptomycin 6-kinase and ribosomal affinity to streptomycin in self-protection of streptomycin producer. Biotechnology Letters 7, 357362.

SugiYama, M., Mochizuki, H., Nimi, O. \& Nomi, R. $(1981 b)$. Mechanism of protection of protein synthesis against streptomycin inhibition in a producing strain. Journal of Antibiotics 34, 1183-1188.

SUTER, M., HÜTTER, R. \& LeISINGER, TH. (1978). Mutants of Streptomyces glaucescens affected in the production of extracellular enzymes. In Genetics of the Actinomycetales, pp. 61-64. Edited by E. Freerksen, I. Tarnok \& J. H. Thumin. Stuttgart \& New York: Gustav Fischer Verlag.

VINING, L. C. (1979). Antibiotic tolerance in producer organisms. Advances in Applied Microbiology 25, 147168.

WALKER, J. B. (1975a). Streptomycin-6-P phosphohydrolase. Methods in Enzymology 43, 465-470.

WALKER, J. B. (1975b). ATP: streptomycin 6-phosphotransferase. Methods in Enzymology 43, 628-632.

Walker, J. B. \& Skorvaga, M. (1973). Phosphorylation of streptomycin and dihydrostreptomycin by Streptomyces. Enzymatic synthesis of different diphosphorylated derivatives. Journal of Biological Chemistry 248, 2435-2440.

WEBER, W., ZäHNER, H., Siebers, J., SCHRÖDER, K. \& ZEECK, A. (1979). Stoffwechselprodukte von Mikroorganismen. 175. Mitteilung. Tetracenomycin C. Archives of Microbiology 121, 111-116.

WEBER, W., ZÄHNER, H., SiEBERS, J., SCHRÖDER, K. \& ZEECK, A. (1981). Tetracenomycins - new antibiotics from Streptomyces glaucescens. Zentralblatt für Bakteriologie, Mikrobiologie und Hygiene (supplement) 11, 465-468.

Yamamoto, H., Hotta, K., OKami, Y. \& UmeZawa, H. (1981). Ribosomal resistance of an istamycinproducer, Streptomyces tenjimariensis, to aminoglycoside antibiotics. Biochemical and Biophysical Research Communications 100, 1396-1401. 